Motrivivência $\quad$ Ano XX, No 31, P. $09-18$ Dez./2008

\title{
Os Conteúdos da Educação Fisica na Escola: entre a promessa e o feito. $O$ que fazer?
}

É quando esquecemos todos os nossos conhecimentos é que começamos a saber...

(Clarice Lispector ${ }^{1}$ )

\section{A presença dos conteúdos nas diversas edições da Mo- trivivência}

Quando está em jogo o debate sobre a ampla e multidisciplinar problemática dos conteúdos da Educação Física na escola, pode-se dizer que a Motrivivência já vem veiculando reflexões que, de forma velada e explícita, direta e indiretamente, abordam a discussão sobre os conteúdos e os tratos para com o conhecimento na Educação Física escolar, especialmente acerca da relação teoria-prática, sobretudo, no que diz respeito às repercussões do debate acadêmico na prática concreta dos professores e professoras que atuam nas escolas. Neste sentido, pode-se dizer que esta revista já havia iniciado este percurso investigativo a partir do da sua $1^{a}$ edição temática, publicada em 1988. Naquela edição, já indagava o currículo dos cursos de Educação Física, sobretudo, no que tange a questões polêmicas ainda hoje de suma atualidade, tais como: Currículo e ideologia; Licenciado elou Bacharelado: alguns entendimentos possíveis; Reformulação dos currículos de formação em Educação Física; Reestruturação dos cursos de graduação em Educação Física e outras questões de caráter

1 LISPECTOR, Clarice. Uma aprendizagem ou o livro dos prazeres. Rio de Janeiro: Rocco, 1998. 
teórico-metodológico. Na mesma perspectiva, o número 4 (1993), intitulado Educação Física Escolar e o compromisso com a escola pública, traz para a análise questões como: o Cotidiano da Educação Física Escolar, Concepção de aulas abertas, Plano Diretor para Educação Física, Tendências Pedagógicas da Educação Física, entre outras.

O número 2 (1989) teve como tema $\mathrm{O}$ esporte e suas diversas concepções, trazendo subsídios para pensar o esporte na sociedade e, consecutivamente, de forma mais teórica, o esporte como conteúdo da Educação Física. Este mesmo teor pode ser verificado no número 9 (1996), cujas abordagens teóricas sobre o jogo podem ter contribuído para pensar este conteúdo determinante para as aulas de Educação Física Escolar.

De forma mais direta, é no número 8 (1995) que aparecem as preocupações filosóficas em torno das dimensões teórico-práticas, enquanto possíveis subsídios para pensar as práticas corporais e seus conteúdos nas escolas. Esse fato é visível já no título do editorial: Teorizando sobre a nossa prática e praticando as teorias nossas de cada dia; e na pergunta formulada para a seção Ponto de Vista: "Na prática, a teoria é outra. Será mesmo?" Esta pergunta é respondida, filosoficamente, nos artigos e seções da revista.
A trajetória reflexiva e crítica sobre o papel da Educação Física na escola continua seu curso no número 13 (1999). Assim, o tema é delimitado tendo como eixo de análise os Elementos teóricometodológicos para a Educação Física. Neste âmbito, o editorial traz a metáfora de que Caminhos não há, mas os pés na grama os inventarão (Ferreira Gullar), tendo como intenção direcionar as reflexões para as questões epistemológicas acerca do cotidiano da Educação Física, assim como [...] refletir sobre os avanços e retrocessos da produção científica,em especial, dos anos 80 e, conseqüentemente, das repercussões das políticas públicas para o desenvolvimento da área ( $\left.L D B, P C N^{\prime} s\right)$. Esta edição ocupa-se na abordagem, como de costume, de temas como: estágio supervisionado, prática de ensino, conteúdos, Educação Física na Educação Infantil. Por fim, tenta responder a questão: "Do ponto de vista das práticas cotidianas da educação Física, quais as metodologias de ensino predominantes e os seus pressupostos teóricos subjacentes?" Esta questão, a nosso ver, possui íntimas relações com tema da presente edição: Os conteúdos da Educação Física na escola.

Ao propor o tema desta edição, o que se pode perceber é que os conteúdos da Educação 
Física aparecem também de forma mais contundente no número 28 (2007); cognominado Conhecimento e prática na Educação Física Escolar, traz para o debate, já em seu editorial, a seguinte reflexão indagativa: "Educação Física Escolar: Conhecimentos da/para a prática?" Este mesmo número continua buscando "respostas" às sempre atuais, pertinentes e relevantes perguntas tais como: Qual a relação entre as teorias críticas da Educação Física e a prática pedagógica na escola. Sob esta mesma ótica, volta a discutir a relação teoria e prática, tendo como um dos eixos norteadores no texto: Educação Física Escolar: a difícil e incontornável relação teoria e prática. Continuando na direção epistemológica e teórico-metodológica, esta mesma edição volta a fomentar discussões em torno do texto Relações entre conhecimento e prática pedagógica no campo da Educação Física.

Diante de toda essa trajetória de produção e veiculação do conhecimento, voltada à reflexão dos problemas e questões de relevância pública, esta revista direciona o seu foco para os conteúdos da Educação Física na escola. Tal fato pode ser percebido, nas temáticas anteriores, as quais já abordavam questões diretamente imbricadas com o tema atual, assim como os temas mais amplos de natureza multidiscipli- nar (gênero, corpo, meio ambiente, mídia, políticas públicas e outros), como por exemplo,o tema formação (números 25 e 26, 2006) e outros, nos quais, é possível perceber as possíveis relações diretas e indiretas) com o tema deste número.

Por fim, o número 29 traz em alguns de seus artigos a preocupação para com As Especificidades e os possíveis conteúdos da Educação física na educação Infantil. Aliás, está preocupação encontra-se em todos os níveis de ensino, conforme constatações empíricas, verificadas nos relatórios do Estágio do Curso de Licenciatura do CDS/UFSC, cujos alunos foram convidados e respondem à pergunta do Ponto de Vista da presente edição: "É possível tematizar outros conteúdos na Educação Física escolar, além das quatro modalidades esportivas tradicionais?"

\section{O que são conteúdos? Quais os conteúdos da Educação Física na escola?}

Como se pode perceber na própria trajetória da revista, o tema conteúdo não é tratado de forma reduzida. Ao que tudo indica, o termo não aparece subjacente aos demais temas numa perspectiva meramente técnico-instrumental. Com efeito, a escolha do tema desta edi- 
ção tem como pressuposto a idéia de conteúdo, compreendido como conhecimento signicativo e qualitativo que dá sentido e significado às experiências da cultura corporal no processo ensino e aprendizagem. Isto posto, o processo de formação político-pedagógica implica discutir o conceito de conteúdo à luz de suas perspectivas teórico-práticas, teórico-metodológicas, em suma, epistemológicas, ontológicas e político-pedagógicas.

Pensando deste modo, os conteúdos da Educação Física escolar tem como cerne a cultura corporal e de movimento, cuja compreensão de corpo e movimento implica a relação entre o corpo produtivo e o corpo brincante ${ }^{2}$, entre o corpo que trabalha e o corpo do "lazer", entre tabalho produtivo e trabalho escolar. Essas preocupações pretendem valorizar os conteúdos, enquanto mediadores do processo ensino-aprendizagem e processo de dimensões ético-estéticas e de animação sócio-educativo, sóciocultura, sócio-política.

De acordo com o Coletivo de Autores $^{3}$, os conteúdos devem ser compreendidos como conhecimento de que trata uma disciplina, sistematizado e distribuído, que geralmente se denomina conteúdos de ensino. Assim, os conteúdos ou conhecimento de que trata a Educação Física na escola tem seu foco para os temas ou formas de atividades, particularmente corporais, tais como: jogo, esporte, ginástica, dança, lutas e outras.

O estudo desses conhecimentos visam a apreender a expressão corporal como linguagem ${ }^{4}$. Nesta direção, conteúdos de ensi$n o^{5}$ podem ser considerados como os conteúdos culturais universais que se constituíram em domínios de conhecimento relativamente autônomos, incorporados pela humanidade, mas permanentemente reavaliados de acordo com as demandas e realidades sociais. Essas reflexões devem considerar o processo histórico que nos antecede, isto é, processo que nos antecede e que vem se desenvolvendo antes da nossa existência, que nos envolve no presente e, neste sentido, também construído e reconstruído. Os conteúdos culturais (de lazer)

2 SILVA, Maurício R. Trama Doce-Amarga: exploração do trabalho infantil e cultura lúdica. São Paulo: HUCITEC; ljuí: UNIJUÍ, 2003.

3 COlETIVO DE AUTORES. Metodologia do Ensino de Educação Física. São Paulo: Cortez, 1992.

4 Quanto a esse respeito, sugerimos a leitura dos livros da coleção Práticas Corporais, organizado pelo NEPEF-Núcleo de Estudos Pedagógicos em convênio com o Ministério dos Esportes/Rede CEDES, disponíveis em http://www.esporte.gov.br/sndel/esporteLazer/cedes/publicacoes.jsp .

5 Ibid 
não existem em abstrato, fora da realidade social. Em suma, a realidade social e os conteúdos culturais são construções humanas que, por serem humanas são históricas, são, simultaneamente, passíveis de mudanças sociais, culturais e econômicas. ${ }^{6}$

Deste modo, o que se pretende analisar a constituição histórica da cultura corporal e de movimento, compreendendo que suas raízes estão na relação homem-natureza, na ação humana de transformar a natureza para dela retirar sua subsistência. As primeiras ações humanas sobre a natureza constituiram as sociedades e seus diferentes modos de produção. A relação homem-natureza possibilitou a realidade córporea humana. Essas reflexões apontam, ao mesmo tempo, para a necessidade e possibilidade da reflexão sobre os conteúdos estruturantes, em cujo bojo teórico-metodológico está implícita a idéia da abordagem pedagógica das diversas manifestações corporais que foram se constituindo ao longo do desenvolvimento histórico da humanidade 7 . Isto significa dizer que os métodos de ensino com base na pedagogia crítico-social dos conteúdos, devem partir, não de conhecimentos artificais, mas de uma relação com as experiências concretas dos alunos. Nisto tudo, o que importa é o privilegiamento da aquisição de conhecimentos ligados às realidades sociais,ou seja, vai-se da ação à compreensão e da compreensão à ação. Os conteúdos representam o elemento dominante em torno do qual se realiza a atividade de estudo. Neste sentido, a aprendizagem não resulta, pura e simplesmente, das necessidades e interesses internos dos sujeitos (crianças e jovens); também não é um processo no qual estes sujeitos escolhem o que fazer. Antes de tudo, a aprendizagem dos conteúdos tem como pressuposto um processo no qual eles se desenvolvem e modificam suas forças físicas e mentais por influência dos conhecimentos, experiências e atividades vindas do entorno social, ou seja, da experiência humana acumulada pelas gerações ao longo da História ${ }^{8}$. É, portanto, nesta ótica que ganham força as perguntas que não querem calar: Afinal, quais são os conteúdos da Educação Física

6 VAGO, Tarcísio Mauro. A essência da vivência lúdica de conteúdos culturais. In: PREFEITURA MUNICIPAL DE BELO HORIZONTE. O lúdico e as políticas públicas: realidade e perspectivas. Belo Horizonte: PBH/SIMES, 1995.

7 SECRETARIA DE EDUCAÇÃO DO PARANÁ (vários autores). Educação Física no Ensino Médio. Curitiba: SEED-PR, 2006.

8 LIBÂNEO, José Carlos. Didática. São Paulo: Cortez, 1992. 
na escola?Por que professores e professoras saem da universidade e encontram dificuldade em articular a prática pedagógica com as dimensões indissociáveis entre compromisso político e a competência técnica?

Pensar os conteúdos na Educação e, em especial, na Educação Física, implica recuperar uma velha-nova questão: o debate em torno da relação entre competência técnica e compromisso político. A esse respeito, vale lembrar o interessante debate entre Saviani, Paulo Nosella e Guiomar Namo de Melo, acerca do compromisso política e da competência ténica. Saviani chega a conclusão de que não há oposição entre esses dois pomos e que nós estamos ainda na fase romântica, na educação, do compromisso político em si. Isto nos leva a pensar que é preciso identificar os fins, implicando, consecutivamente, a realação dialética entre competência técnica e compomisso político. Para tanto, é preciso compreender que afirmação do saber universal não pode ser abstrata e ahistórica; e que que assim, do mesmo modo, a sua negação resulta abstrata e ahistorica9 .

Por tudo o que já foi supramencionado, o tema Conteúdos da Educação Física Escolar neste número se justifica levando-se em conta, de um lado, uma grande produção do conhecimento acerca dos elementos teórico-metodológicos da área, anteriormente mencionados, $\mathrm{e}$ de outro lado, há enormes reclamos em torno da falta de aproximações mais concretas entre o que promete a teoria e as reais demandas em termos dos conteúdos desenvolvidos nas aulas de Educação Física escolar. Há hipóteses de que, apesar de propostas pedagógicas e teóricometodológicas e já consolidadas na área, não consigam dar conta do direito das crianças e jovens aos conteúdos culturais da Educação Física (jogos, lutas, dança, esporte e ginástica). Esse fato pode ser visualizado nos estágios supervisionados, nos cursos de formação continuada e nas próprias aulas de Educação Física nas escolas. Sem generalizões, o que se observa e se ouve como argumento de professores e crianças é a denúncia da predominância da monocultura esportiva (futebol), o laissez fair escolanovista (ex: entregar a bola e deixar rolar e deixar os alunos aprenderem a partir da experiência dos alunos), falta de equipamentos e espaços, baixos salários dos professores e a influência da indústria esportiva, imposta pela mídia, sobre as práticas corporais.

9 SAVIANI, Dermeval. Pedagogia Histórico-Crítica: Primeiras Aproximações. São Paulo: Cortez/ Autores Associados, 1991. 
Os conteúdos da Educação Física e a necessidade de pesquisas como estratégia de inovação educativa e abordagens práticas ${ }^{10}$

Diante da multimensionalidade da problemática em torno dos tratos para os conhecimentos/ conteúdos nas aulas de Educação Física na escola, talvez fosse relevante dois procedimentos: a) Recuperar o debate epistemológico acumulado na produção do conhecimento acerca das tendências da Educação Física nos anos 80,90 e 2000; b) Resgatar e atualizar a produção do conhecimento, de caráter mais propositiva, que aborda o trato para os conteúdos da Educação Física' ${ }^{11}$; c) Analisar as propostas governamentais (em níveis municipais, estaduais e federais - PCN's) para a Educação Física escolar, a partir dos seguintes documentos: Contribuição ao debate do currículo em Educação Física: Uma proposta para a escola pública/Secretatia de Educação do Estado de Pernambuco (1990); Diretrizes Curriculares para a Educação Física no Ensino Fundamental e na Educação Infantil da Rede Munici- pal de Florianópolis (1993-1996); EducaçãoFísica: Ensino Médio/Secretaria de Estado da Educação do Paraná (2006) e outros; d) Realizar o debate sobre os conteúdos/conhecimentos, articulado com o debate crítico acerca das Diretrizes Curriculares (divisão entre bacharelado e licenciatura), regulamentação da profissão e as ingerências do sistema CONFEF/CREF.

Os pontos sugeridos não se constituem numa proposta delimtada de pesquisa sobre os tratos para com os conhecimentos/conteúdos, mas sim numa agenda provisória e propositiva que, somada aos textos desta edição, poderão, simultaneamente, fomentar e ampliar o debate, a produção e a veiculação do conhecimento a esse respeito, em especial, no âmbito da formação continuada. Neste sentido, a título de exemplificação, poderíamos trazer à tona a seguinte questão: $E d u$ cação Física Escolar: temos o que ensinar? Esta pergunta, formulada em 1998, traz em suas entrelinhas as reflexões, de suma atualidade, em torno do tema Considerações acerca do Conhecimento(Re)conhecido pela Educação Física Escolar. Com base nisso, fica para reflexão a

10 GAMBOA, Silvio S. Pesquisa em Educação: Métodos e Epistemologias. Chapecó: Argos, 2007.

11 Além do já citado Metodologia de Ensino da Educação Física (Coletivo de Autores, 1992), sugerimos também: Visão Didática da Educação Física (Grupo de Trabalho Pedagógico UFPE/UFSM - Livro Técnico, 1991) e Transformação Didático-pedagógica do Esporte (Elenor Kunz - Ed. UNIJUI, 1994). 
seguinte pergunta-síntese: $O$ que a Educação Física e seus profissionais precisam conhecer e reconhecer como conhecimento a ser reconhecido? Dito de outra forma, o que está sendo ensinado(conteúdos/conhecimentos nas aulas de Educação Física nas escolas? ${ }^{12}$

Ao que tudo indica, a produção do conhecimento existente, com sua contribuição paradimática, consubstanciada pelas tendências crítico-superadora ${ }^{13}$, críticoemancipatória ${ }^{14}$ e aulas abertas ${ }^{15}$, cumprem o seu papel filosófico no que pese a posição crítica que desenpenham em termos epistemológicos. Quanto a isso, a reflexão sobre conteúdo não deve ter um caráter prescritivo e reprodutivista, mas sim na perspectiva dos pares dialéticos teoria-prática, reflexãoação, ensino-aprendizagem, eninopesquisa e outros. Aliás, quanto a relação ensino-pesquisa nos cursos de Educação Física, não seria o caso de se buscar as possíveis relações entre a relação teoria e prática pedagógica na Educação Física Escolar, articuladas com o processo de construção da pesquisa como estratégia de inovação educativa e suas abordagens práticas? Além disso, talvez não fosse interessante em apostar em problemas de pesquisa que fossem ao mesmo tempo projetos de intervenção, visando, com isso, níveis de mudança, verificados a partir de abordagens participativas de pesquisa (pesquisa participante e pesquisação)? ${ }^{16}$

O desafio que se coloca é pensar a transformação dos problemas do cotidiano da Educação Física em problemas de investigação, ou seja, do particular ao universal e vice-versa. Isso implicaria em considerar e destacar os problemas de relevância pública (situação de impasse e necessidade), ou melhor, os "problemas significativos" de "caráter universal", que emergem do "real" e se articulam com os "problemas específicos" que emergem da realidade das aulas de Educação Física nas escolas.

Todo esse processo heurístico-investigativo poderia demandar em enormes desafios, considerando, simultaneamente, a revisão dos pressupostos teórico-metodológicos que norteiam as propostas pedagó-

12 CAStellani FilHO, Lino. Política Educacional e Educação Física. Campinas/SP: Autores Associados, 1998

13 COLETIVO DE AUTORES, já referido.

14 KUNZ, Elenor. Transformação Didático-Pedagógica. ljuí: UNIJUÍ, 1994.

15 HILDELBRANDT, Reiner; LAGING, Ralf. Concepções Abertas no Ensino da Educação Física. Rio de Janeiro: Livro Técnico, 1986.

16 GAMBOA, Silvio S. Pesquisa em Educação: Métodos e Epistemologias. Chapecó: Argos, 2007. 
gicas atuais e, ao mesmo tempo, um novo processo de problematização permanente sobre a legitimidade da Educação Física escolar (pesquisa como estratégia de inovação educativa) e a re-signicação de seus conteúdos. As reflexões supracitadas terminam por recuperar um assunto de suma atualidade na área, a saber: A Educação Física e a busca de legitimidade pedagógica ${ }^{17}$. Isto implicaria em considerar os últimos acontecimentos político-ideológico e pedagógicos, em torno das seguintes questões polêmicas: regulamentação da profissão, reflexões epistemológicas sobre o papel da Física (prática pedagógica ou uma ciência?).

Diante do exposto, talvez tivéssemos que fazer algumas perguntas provisórias, tais como: 1) em que medida os caminhos teórico-metodológicos até agora trilhados, em termos de conceções pedagógicas (ex: propositivas e não propositivas) ${ }^{18}$, dão conta em enfrentar a dinâmica do cotidiano das aulas de educação Física nas escolas? 2) o que se entende por conteúdo na perspectiva pedagógica da educação Física? 3) quais são, efetivamente, os "conteúdos" da Educação Física Escolar (que tipo de aula está sendo dada nas escolas)?; 4) quais os fatores concretos que impedem a implementação de mudanças e inovações, para que exista uma relação entre teoria e prática, tanto no contexto da formação acadêmica (graduação) quanto na pós (especialização, mestrado e doutorado)? 5) quando se analisa cada um dos conteúdos da Educação Física (dança, ginástica, jogos, lutas, esportes e outros), que perguntas poderíamos formular para que novos problemas de pesquisa possam emergir (ex: na dança, no esporte, nos jogos etc.), no sentido da reflexão sobre os limites e possibilidades destes? Finalmente, uma última questão se coloca no âmbito do chamado "lazer" na sociedade capitalista e seus conteúdos culturais (recreação): não seria conveniente redimensionar os conteúdos culturais do lazer ou "interesses do lazer $^{\prime \prime 19}$, considerando as relações com outras instâncias da vida cotidiana como as artes cênicas, visuais e plástica, o turismo, etc.?

No projeto visual desta edição, temos as belas fotos de Paulo Cesar de Carvalho Lima, que ilustram tanto nossa capa quanto a seção Imagens e Homenagens. As

17 BRACHT, Valter. Educação Física e Aprendizagem Social. Porto Alegre: Magister, 1992.

18 CASTELLANI FILHO. A Educação Física no Sistema Educacional Brasileiro: percurso, paradoxos e perspectivas. Tese (Doutorado em Educação). Campinas: Faculdade de Educação, UNICAMP, 1999.

19 DUMAZEDIER, Joffre. Valores e Conteúdos Culturais do Lazer. São Paulo: SESC, 1980. 
fotografias fazem parte do acervo pessoal do artista, tendo sido apresentadas em exposições realizadas no Espaço Cultural da Caixa Econômica Federal, de São Paulo (2004), e em Salvador (2005), além de integrarem sua Monografia de Conclusão do Curso de Especialização, com o título Escola Pública: retratos dos espaços para a construção da cultura corporal20.

Para encerrar, fazemos a homenagem especial neste número para o professor Vitor Marinho de Oliveira. Com ele, iniciamos homenagens em vida àqueles que constroem a história do presente, porém sem deixar de considerar a memória dos que já se foram. Vitor Marinho é um dos mais importantes representantes do pensamento pedagógico crítico da Educação Física brasileira e continua deixando, a cada dia, novos legados, para além dos livros O que é Educação Física, Educação Física Humanista e Consenso e Con- flito na Educação Física Brasileira. A história do Vitor Marinho pode ser exemplificada com o belo verso de Mário Quintana: “o passado não reconhece o seu lugar - está sempre presente....". Aliás, ao escrever este editorial, soubemos da notícia do falecimento do grande poeta baiano Damário Dacruz, que ilustrou o editorial desta revista em seu número 4 (Tema: A Educação Física escolar e o compromisso com a escola pública), cujos versos assim diziam:

\section{"Toda manhã é dura e só muda com} luta (...). Amanhecemos com os olhos do amanhã e o dia é hoje".

Florianópolis, outuno de 2010.

Maurício Roberto da Silva Giovani De Lorenzi Pires Editores 